\title{
$\beta$-Endorphin Involvement in the Antidopaminergic Effect of Caerulein
}

\author{
Katsuaki MATSUBARA and Akira MATSUSHITA \\ Shionogi Research Laboratories, Shionogi \& Co., Ltd., \\ Fukushima-ku, Osaka 553, Japan \\ Accepted November 30, 1985
}

\begin{abstract}
Caerulein has been shown to possess a long-lasting antagonistic effect on amphetamine hyperactivity in rats when given in combination with haloperidol. We found that this effect of caerulein involved $\beta$-endorphin. Naloxone pretreatment and hypophysectomy abolished the caerulein effect, while intracerebroventricular or intra-nucleus accumbens injection of $\beta$-endorphin together with haloperidol administration produced an effect similar to that of caerulein. The results suggest that the long-term antagonism of the amphetamine effect of caerulein is mediated by the endogenous opioid $\beta$-endorphin.
\end{abstract}

Caerulein (CLN), a decapeptide chemically related to cholecystokinin octapeptide (CCK8 ), has been found to result in a long-lasting antagonistic effect on amphetamine (AMP) hyperactivity in rats when given together with haloperidol (HLP) (1). Also, we reported the pharmacological analysis of the nature of this long-term effect (2). In addition, a recent study showed that CLN may indirectly modulate some dopaminergic activity in the central nervous system (3). However, at present, the mechanism producing this effect remains to be elucidated.

CLN and CCK-8 have been shown to directly affect the anterior pituitary lobe or the hypothalamus in rats, suggesting that they play an important role in regulating the secretion of pituitary hormones (4-6). Furthermore, in humans, CLN significantly increases $\beta$-endorphin ( $\beta$-END) levels in plasma and cerebrospinal fluid (7-9). It was also demonstrated that $\beta$-END modulates some dopaminergic systems to influence a variety of behavioral phenomena, i.e., changes in motoric behavior such as stereotypy. cataleptic posturing, and spontaneous activity $(10,11)$.

Thus, our interest was directed to search for interaction between $\beta$-END and the CLN effect. The present study was done to investigate whether $\beta$-END is involved in producing the long-term effect of CLN on AMP-induced hyperactivity in rats.

\section{Niaterials and Methods}

Animals: Male Wistar rats, purchased from Shizuoka Laboratory Animal Center, Japan, were $250-300 \mathrm{~g}$ at the beginning of the experiments. They were housed in groups with free access to food and water on an 8 a.m.-8 p.m. lighting schedule during the experiments.

Hypophysectomy: Hypophysectomy was performed through the external auditory canal by the modified method of Tanaka (12). The animals were allowed at least 1 week to recover from the operation before the experiment.

Cannulae implantation: A stainless steel guide cannula for the right lateral ventricle or bilateral cannulae for the nucleus accumbens was implanted using the optical brain tracer technique (13). The injection units, $0.31 \mathrm{~mm}$ in diameter, were terminated $1.5 \mathrm{~mm}$ below the guide tips, so that the drug was deposited at the site with the following König and Klippel coordinates (14): A 6.4, L 1.4, H 1.8, in the lateral ventricle: A 9.4, L 1.4, H - 0.6. in the nucleus accumbens. The animals were allowed 1 week to recover before testing. $\beta$ END was injected into the lateral ventricle in a volume of $5 \mu$ over a period of $30 \mathrm{sec}$ or 
into the nucleus accumbens bilaterally in a volume of $0.4 \mu \mathrm{l}$ over a period of $10 \mathrm{sec}$ through an injection cannula passed into each guide cannula.

Experimental procedures: On the 1st day, intact animals in four equal groups $(n=24)$ were administered with naloxone (NX, 0.5 $\mathrm{mg} / \mathrm{kg}$ ) and then $15 \mathrm{~min}$ later, were injected with saline, HLP $(0.1 \mathrm{mg} / \mathrm{kg}), \mathrm{CLN}(40 \mu \mathrm{g})$ $\mathrm{kg}$ ), or a combination of CLN and HLP. After $60 \mathrm{~min}$, all groups received AMP (2 mg/ $\mathrm{kg}$ ). At 30 min after AMP administration, each rat was placed in an open field apparatus (15). and its ambulatory activity was measured for $3 \mathrm{~min}$. On the $2 \mathrm{nd}$, 8 th or 15 th day, each rat was injected with AMP (2 mg/ $\mathrm{kg}$ ) alone, and $30 \mathrm{~min}$ later, the activity was measured as on the 1 st day. Hypophysectomized rats in four equal groups $(n=20)$ were subjected to experimental procedures similar to those for the intact rats except for pretreatment with NX. Six equal groups of rats $(n=30)$ with intracerebroventricular or intra-nucleus accumbens injection units were given $\beta$-END instead of CLN into the brain, with the other procedures being the same as those for intact rats except for NX pretreatment.

Drugs: Caerulein (ceruletide diethylamine, synthesized in our laboratory), dl-amphetamine sulfate (Zedrin, Takeda), haloperidol (Shionogi), naloxone hydrochloride (Endo Laboratory), and $\beta$-endorphin (Osaka Protein Research Foundation) were used. All drugs were dissolved in saline and administered subcutaneously except for intracranial injection of $\beta$-END.

Statistical analysis: The experimental results were analyzed by Dunnett's $t$-test for multiple comparison following one-way analysis of variance.

\section{Results}

Effect of naloxone: Previous reports (1,2) described the long-lasting antagonistic effect of CLN on AMP-induced hyperactivity in rats, when the peptide was given in combination with HLP, and briefly mentioned the dose-dependency of the duration of CLN action; the effect lasted for 14 days at $40 \mu \mathrm{g} /$ $\mathrm{kg}$ of CLN.

In the present experiment with intact animals pretreated with NX $(0.5 \mathrm{mg} / \mathrm{kg})$. drug treatment with HLP or a combination of HLP and CLN significantly reduced AMPinduced hyperactivity on the first day in comparison with the saline-treated control group (Fig. 1; $F=48.21$, df $3 / 20, P<0.01$ ). On the 2nd day, however, no significant reduction in the AMP effect was found in the HLP plus CLN group (Fig. $1 ; F=0.76$, df $3 / 20$, $P>0.05)$, unlike the results of the previous reports $(1,2)$. Systemic administration of the opiate antagonist NX blocked the long-term antagonistic effect of CLN on AMP-induced hyperactivity.

Effect of hypophysectomy: On the 1st day, the hypophysectomized rats treated with HLP or HLP plus CLN were less sensitive to AMP (Fig. 2; $F=18.92$, df 3/20, $P<0.01$ ). On the 2 nd day, no significant differences were found among the four groups (Fig. 2; $F=0.89$, df $3 / 20, P>0.05)$. Hypophysectomy abolished the long-term effect of CLN on AMP-induced hyperactivity, similar to the result of NX pretreatment.

Effect of intracerebroventricular or intra-

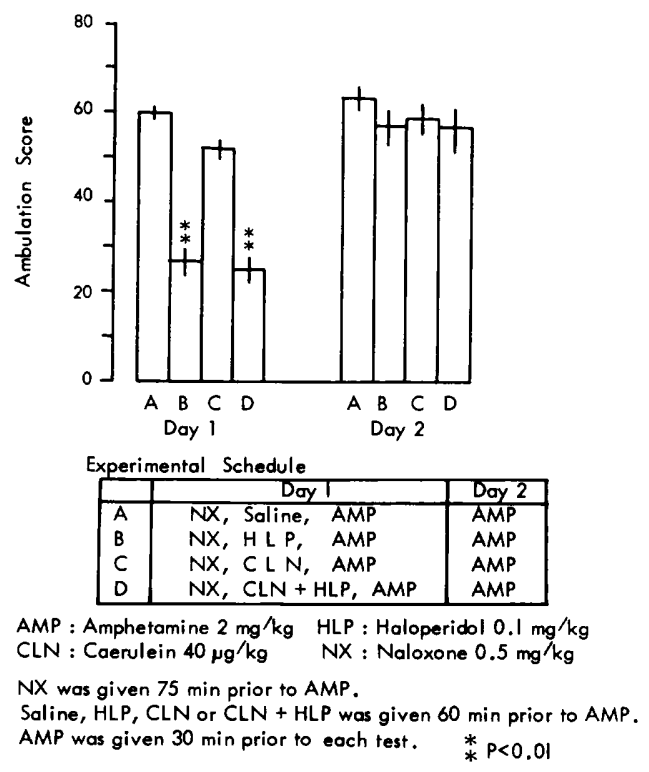

Fig. 1. Absence of the long-term antagonistic effect of caerulein with haloperidol on amphetamine hyperactivity in rats following naloxone pretreatment and experimental schedule. Results are expressed as the mean $\pm S$.E. of 6 animals. Statistical comparisoris between group $A$ and the other groups were based on Dunnett's $t$-test. ( $\left.{ }^{* *} P<0.01\right)$ 
nucleus accumbens injection of $\beta$-endorphin: Animals intracerebroventricularly injected with $0.625,2$ or $10 \mu \mathrm{g}$ of $\beta$-END on the $1 \mathrm{st}$ day showed normal responses to AMP, but those given HLP alone or HLP plus $\beta$-END showed significantly reduced responses (Fig. 3: $F=20.63$, df 7/32, $P<0.01)$. On the 2 nd day, four groups given HLP alone or each dose of $\beta$-END alone on the 1 st day displayed normal susceptibility to AMP. whereas the groups treated with HLP plus each dose of $\beta$-END were still less susceptible to AMP (Fig. 3; $F=19.81$, df 7/32, $P<0.01$ ). On the 8th day, the response to AMP of animals that received HLP plus $10 \mu \mathrm{g}$ of $\beta$ END was still significantly reduced (Fig. 3; $F=2.41$, df 7/32, $P<0.05$ ), but normal susceptibility was regained by the 15 th day $(F=0.37$ : df 7/32, $P>0.05)$. Thus, the duration of long-lasting reduction in AMP hyperactivity elicited by both injection of HLP and intracerebroventricular injection of $\beta$ END depended on the $\beta$-END dose on the 1 st day.

In a separate experiment, animals were

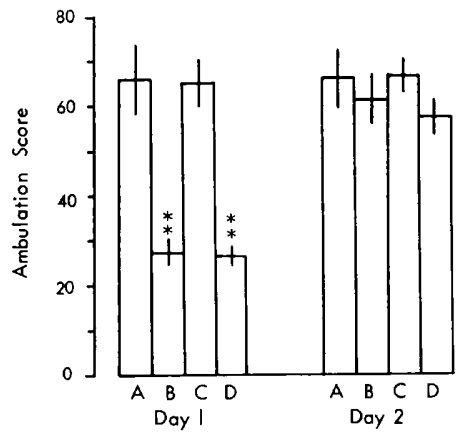

\begin{tabular}{|c|c|c|}
\hline \multicolumn{3}{|c|}{ Experimental } \\
\hline & Day 1 & Day 2 \\
\hline $\bar{A}$ & Saline, AMP & AMP \\
\hline B & $H L P, \quad A M P$ & AMP \\
\hline C & $C\llcorner N, \quad A M P$ & AMP \\
\hline D & $\mathrm{CLN}+\mathrm{HLP}, \mathrm{AMP}$ & AMP \\
\hline
\end{tabular}

AMP: Amphetamine $2 \mathrm{mg} / \mathrm{kg}$ HLP: Haloperidol $0.1 \mathrm{mg} / \mathrm{kg}$ CLN : Coerulein $40 \mu \mathrm{g} / \mathrm{kg}$

Saline, HLP, CLN or CLN + HLP was given $60 \mathrm{~min}$ prior to AMP. AMP was given $30 \mathrm{~min}$ prior to each test. $\quad * P<0.01$

Fig. 2. Absence of the long-term antagonistic effect of caerulein with haloperidol on amphetamine hyperactivity in hypophysectomized rats and experimental schedule. Abbreviations, see Fig. 1.

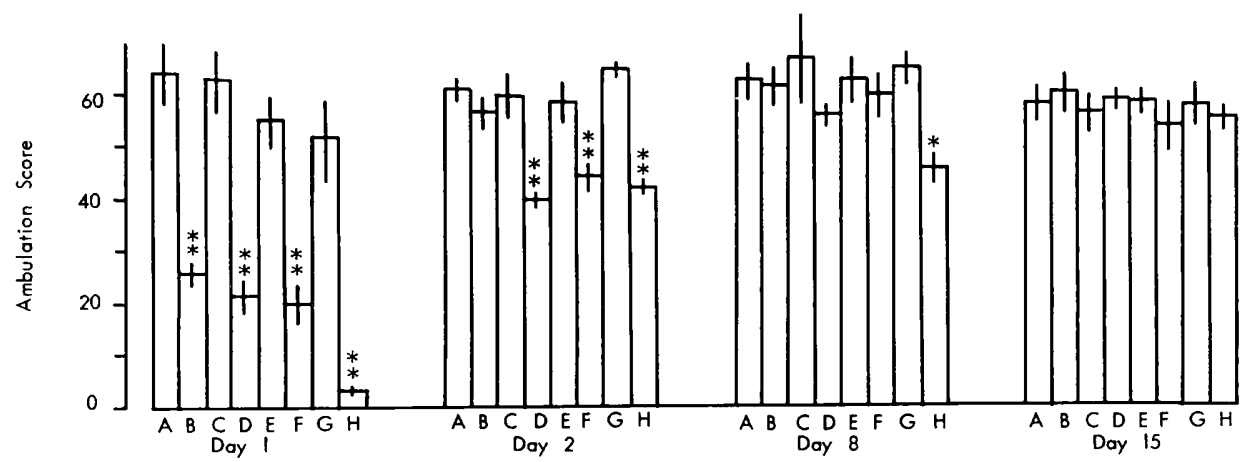

Experimental Schedule

\begin{tabular}{|c|c|c|c|c|c|}
\hline & Day I & & Doy 2 & Day 8 & Day 15 \\
\hline A & Saline (ICV) + Saline, AMP & & AMP & AMP & AMP \\
\hline $\mathrm{B}$ & Saline(ICV) $+H L P, \quad$ AMP & & AMP & AMP & AMP \\
\hline $\mathrm{C}$ & $\beta$-END $(0.625 \mu g$, ICV $)+$ Saline, & AMP & AMP & AMP & AMP \\
\hline $\mathrm{D}$ & $\beta-E N D(0.625 \mu g, I C V)+H L P$, & AMP & AMP & AMP & AMP \\
\hline$E$ & B-END $(2.0 \mu g, I C V)+$ Saline, & AMP & AMP & AMP & AMP \\
\hline$F$ & $\beta-E N D(2.0 \mu g, I C V)+H L P$, & AMP & AMP & AMP & AMP \\
\hline G & $\beta-E N D(10.0 \mu \mathrm{g}, \mathrm{ICV})+$ Saline, & AMP & AMP & AMP & AMP \\
\hline $\mathrm{H}$ & $\beta-E N D(10.0 \mu g, I C V)+H L P$, & AMP & AMP & AMP & AMP \\
\hline
\end{tabular}

AMP : Amphetamine $2 \mathrm{mg} / \mathrm{kg} \quad$ HLP : Haloperidol $0.1 \mathrm{mg} / \mathrm{kg} \quad \beta$-END : $\beta$-Endorphin ICV : Intracerebroventriculor injection Saline(ICV) + Soline, Saline(ICV) + HLP, $\beta$-END(each dose, ICV) + Soline, or $\beta$-END (each dose, ICV) + HLP was given $60 \mathrm{~min}$ prior to AMP. AMP was given $30 \mathrm{~min}$ prior to each test.

* $\mathrm{P}<0.05, \quad * \mathrm{P}<0.01$

Fig. 3. Time course of the antagonistic effect of intra-cerebroventricular injected $\beta$-endorphin with haloperidol on amphetamine hyperactivity in rats and experimenta! schedule. Results are expressed as the mean $\pm S$. E. of 5 animals. Statistical comparisons between group $A$ and the other groups were based on Dunnett's t-test. $\left({ }^{*} \mathrm{P}<0.05,{ }^{*} \mathrm{P}<0.01\right)$ 


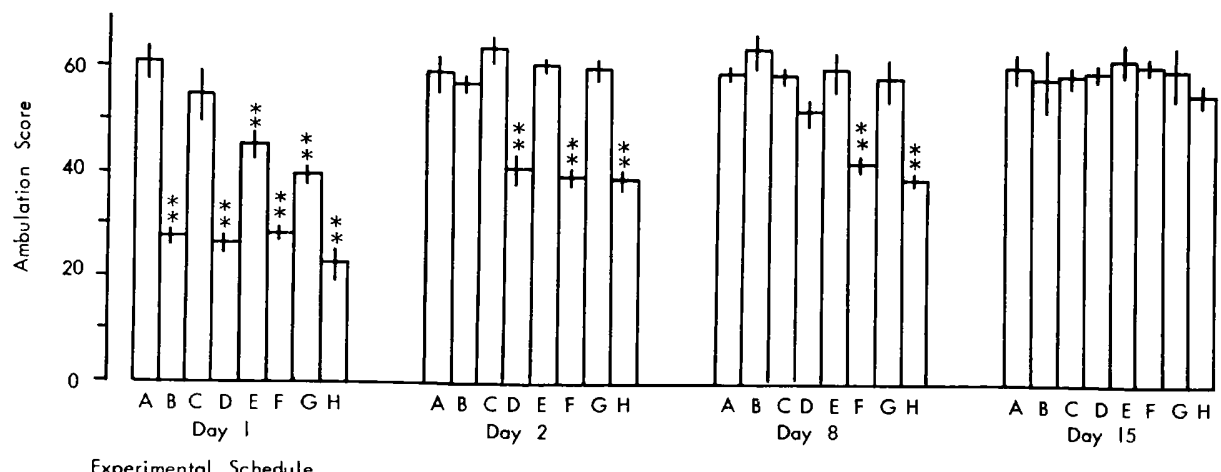

\begin{tabular}{|c|c|c|c|c|c|}
\hline & Day 1 & & Day 2 & Doy 8 & Day 15 \\
\hline A & Saline(NA) + Saline, AMP & & AMP & AMP & AMP \\
\hline B & Saline(NA) + HLP, AMP & & $A M P$ & AMP & AMP \\
\hline C & $\beta$-END $(0.02 \mu \mathrm{g}, \mathrm{NA})+$ Saline, & AMP & $A M P$ & AMP & AMP \\
\hline $\mathrm{D}$ & $\beta-\operatorname{END}(0.02 \mu \mathrm{g}, \mathrm{NA})+\mathrm{H} L \mathrm{P}$, & AMP & AMP & AMP & AMP \\
\hline$E$ & $\beta$-END $(0.2 \mu \mathrm{g}, \mathrm{NA})+$ Saline, & AMP & AMP & AMP & AMP \\
\hline $\mathrm{F}$ & $\beta-E N D(0.2 \mu g, N A)+H L P$, & AMP & AMP & AMP & AMP \\
\hline G & $\beta$-END $(2.0 \mu g, N A)+$ Saline, & AMP & AMP & AMP & AMP \\
\hline $\mathrm{H}$ & $\beta-\operatorname{END}(2.0 \mu \mathrm{g}, \mathrm{NA})+\mathrm{H} L \mathrm{P}$, & AMP & AMP & AMP & AMP \\
\hline
\end{tabular}

AMP : Amphetamine $2 \mathrm{mg} / \mathrm{kg} \quad H L P$ : Holoperidol $0.1 \mathrm{mg} / \mathrm{kg} \quad \beta-E N D: \beta$-Endorphin NA : Intro-nucleus accumbens injection Saline(NA) + Saline, Saline(NA) + HLP, $\beta-E N D($ each dose, NA) + Saline, or $\beta-E N D($ each dose, NA) + HLP wos given $60 \mathrm{~min}$ prior to AMP. AMP was given $30 \mathrm{~min}$ prior to each test. $\quad * P<0.01$

Fig. 4. Time course of the antagonistic effect of intra-nucleus accumbens injected $\beta$-endorphin with haloperidol on amphetamine hyperactivity in rats and experimental schedule. Abbreviations, see Fig. 3.

given intra-nucleus accumbens injections of $0.02,0.2$ or $2 \mu \mathrm{g}$ of $\beta$-END on the 1 st day. The anti-AMP activity of $\beta$-END alone was observed only in the 1 st day test of the groups given 0.2 and $2 \mu \mathrm{g}$. This reduction in AMP hyperactivity is due to an acute $\beta$-END effect and differs in nature from the effect investigated here. In addition, the response to AMP of animals given HLP alone or HLP plus each dose of $\beta$-END was significantly reduced (Fig. 4; $F=20.63$, df 7/32, $P<0.01$ ). On the 2 nd day, four groups given HLP alone or each dose of $\beta$-END alone on the 1 st day showed normal susceptibility to AMP. whereas the groups treated with HLP plus each dose of $\beta$-END were still less susceptible (Fig. 4; $F=26.25$, df 7/32, $P<0.01$ ). On the 8th day, the response to AMP of animals given HLP plus 0.2 or $2 \mu \mathrm{g}$ of $\beta$-END was still significantly reduced (Fig. 4; $F=29.64$, df $7 /$ 32, $P<0.01$ ), but normal response to AMP was regained by the 15 th day. Thus, these results, like those for animals given intracerebroventicular injection of $\beta$-END, clearly demonstrated that the duration of long-term reduction in AMP hyperactivity induced by intra-nucleus accumbens-injection of $\beta$ -
END together with HLP depended on the 1 st day.

\section{Discussion}

Subcutaneous administration of either CLN or CCK- 8 has been shown to produce $\mathrm{NX}$-sensitive antinociceptive effects in mice $(16,17)$. CCK-8-induced effects on both food intake and forestomach motility in sheep was abolished after NX pretreatment (18). These observations suggest that part of the pharmacological effects induced by CLN or CCK- 8 is mediated by an opiate receptor or a release of endogenous opioid peptides. In humans, the analgesic action of CLN was found to be completely antagonized by NX pretreatment, and CLN administration significantly augumented $\beta$-END levels (9).

The present findings indicate that NX pretreatment before the experimental paradigm on the 1st day abolishes the long-term effect of CLN on AMP-induced hyperactivity, suggesting that the CLN effect in this experiment may be also involved in endogenous opioids.

$\beta$-END occurs in the highest concentrations in the anterior and neurointermediate 
lobe of the pituitary. Moreover, its pituitary concentrations are two magnitudes higher than those of other peptides in the pituitary or central nervous system $(19,20)$. In the neurointermediate pituitary, but not in the anterior pituitary, $\beta$-END can be $\alpha-N$ acetylated further at its $\mathrm{N}$-terminus. This modification causes it to lose all its opiatelike properties (21-23).

CCK- 8 has been shown to increase plasma levels of ACTH-like activity, when given intraperitoneally (4). The effect is probably caused by direct action on the anterior pituitary lobe or the hypothalamus. Moreover. CCK- 8 causes release of $\beta$-END immunoreactivity from the anterior pituitary (6).

In the second set of experiments, we used hypohysectomized animals to determine whether pituitary is indispensable for producing the long-lasting effect of CLN on AMP-induced hyperactivity. As CLN in combination with HLP could not induce the long-term effect in these animals, the release of $\beta$-END from the anterior pituitary may play an important role in the production of the CLN effect.

Since CL.N plays a role in regulating $\beta$ END secretion, the third set of experiments were done to examine whether intracranialinjection of $\beta$-END mimics the action of CLN in the present experimental paradigm. Like the effect of $C L N(1,2)$, both intraventricular and intra-nucleus accumbens injection of $\beta$ END produced the long-term and dosedependent reduction of AMP-induced hyperactivity with a smalier dose being needed for the intra-nucleus accumbens injection.

These results suggest that at least the release of $\beta$-END in the nucleus accumbens may be involved in the CLN effect since enhanced locomotor activity elicited by AMP results from releasing dopamine from dopamine nerve terminals in the nucleus accumbens (24-26) and in addition, opiate receptors are located presynaptically on dopaminergic neurons from the nucleus accumbens with mediating presynaptic inhibition of dopamine release (27). At present, no evidence is available for the $\beta$-ENDergic relationship between the nucleus accumbens and the anterior pituitary, and the reason why the long-lasting effect of CLN occurs is still not known.

In conclusion, our study has demonstrated that NX pretreatment and hypophysectomy abolish the CLN effect, and $\beta$-END mimics the long-term effect of CLN, suggesting that the CLN effect may result from mediation by the endogenous opioid $\beta$-END.

Acknowledgement: The authors are very grateful to Prof. Sigmund Hsiao, Department of Psychology, University of Arizona, for the preparation of this manuscript.

\section{References}

1 Matsubara, K. and Matsushita, A.: Long-lasting reduction of amphetamine-induced hyperactivity in rats after combined administration of caerulein with haloperidol. Eur. J. Pharmacol. 101, 157158 (1984)

2 Matsubara, K. and Matsushita, A.: Analysis of the long-lasting antagonistic effect of caerulein on amphetamine hyperactivity in rats. Japan. J. Pharmacol. 38, 381-390 (1985)

3 Matsubara, K. and Matsushita, A.: Possible involvement of the central nervous system in long-term effect of caerulein on amphetamineinduced hyperactivity in rats. Japan. J. Pharmacol. 39, 317-321 (1985)

4 Itoh, S., Katsuura, G., Hirota, R. and Odaguchi, K.: Effect of caerulein on plasma corticosteron concentration in the rat. Life Sci. 27, 22052210 (1980)

5 Porter, J.R. and Sander, L.D.: The effect of cholecystokinin octapeptide on pituitary adrenal hormone secretion. Regul. Pept. 2, 245-252 (1981)

6 Meyer, D.K., Anhut, H., Nutto, D., Beinfeld, M.C. and Knepel, W.: Cholecystokinin release $\beta$ endorphin from the anterior pituitary gland. Neuropeptides 2, 371-375 (1982)

7 Basso, N., Materia, A., D'Intinosante, V. Ginaldi, A., Pona, V., Reilly, P. and Jaffe, B.: $\beta$-Endorphin, substance P, ACTH, prolactin and $\mathrm{GH}$ levels in the plasma and in the cerebral spinal fluid following cerutide infusion in man. Gastroenterology 80, 1105 (1981)

8 Basso, N., Materia, A.. D'Intinosante, V., Ginaldi, A., Pona, V., Reilly, P., Ruggeri, S. and Floravanti M.: Effect of ceruletide on pituitary-hypothalamic peptides and on emotion in man. Peptides 2, Supp. 2, 71-75 (1981)

9 Basso, N., Pona, V., D'Intinosante, V., Fiocca, F., Desantis, C., Bagarani, M., Gizzonio, D. and Ponzielli, F.: Effect of ceruletide on rest pain in patients with arterial insufficiency of the lower extremity. Eur. J. Clin. Pharmacol. 22, 531-533 
(1982)

10 Tseng, L.F., Wei, E.T., Loh, H.H. and Li, C.H.: $\beta$-Endorphin: Central sites of analgesia, catalepsy and body temperature changes in rats. J. Pharmacol. Exp. Ther. 214, 328-332 (1980)

11 Iwamoto, E.T. and Way, E.L.: Circling behavior and stereotypy induced by intraingral opiate microinjections. J. Pharmacol. Exp. Ther. 203, 347-359 (1977)

12 Tanaka, A.: A simple method of hypohysectomy on rats. Ann. Res. Shionogi Res. Lab. 5, 678-680 (1955) (in Japanese)

13 Ikeda, M. and Matsushita, A.: Reflectance of rat brain structures measured by an optical fiber technique. J. Neurosci. Methods 2, 9-17 (1980)

14 König, J.F.R. and Klippel, R.A.: The Rat Brain. A Stereotaxic Atlas of the Forebrain and Lower Parts of the Brain Stem, Williams and Wilkins Company, Baltimore (1963)

15 Matsubara, K. and Matsushita, A: Changes in ambulatory activities and muscle relaxation in rats after repeated doses of diazepam. Psychopharmacology (Berlin) 77, 279-283 (1982)

16 Zetler, G.: Caerulein and cholecystokinin octapeptide produce analgesia and ptosis in mice. Naunyn Schmiedebergs Arch. Pharmacol. 311, Supp. R66 (1980)

17 Zetler, G.: Analgesia and ptosis caused by caerulein and cholecystokinin octapeptide (CCK-8). Neuropharmacology 19, 415-422 (1980)

18 Buéno, L., Duranton, A. and Ruckbusch, Y.: Antagonistic effect of naloxone on CCKoctapeptide induced satiety and rumino-reticular hypermotility in sheep. Life Sci. 32, 855-863 (1983)

19 Seizinger, B.R., Bovermann, K., Maysinger, D., Hölt, V. and Herz, A.: Differential effects of acute and chronic ethanol treatment on particular opioid peptide systems in discrete regions of rat brain and pituitary. Pharmacol. Biochem. Behav. 18, Supp. 1, 361-369 (1983)

20 Pittius, C.H., Seizinger, B.R., Pasi, A., Mehraein, P. and Herz, A.: Distribution and characterization of opioid peptides derived from proenkephalin $A$ in human and rat central nervous system. Brain Res. 304, 127-136 (1984)

21 Smyth, D.G., Massey, D.E., Zakarian, S. and Finnie, D.A.: Endorphiris are stored in biological active and inactive forms. Nature 279, 252-254 (1979)

22 Seizinger, B.R. and Höllt, V.: In vitro, biosynthesis and $\mathrm{N}$-acetylation of $\beta$-endorphin in pars intermedia of the rat pituitary. Biochem. Biophys. Res. commun. 96, 535-543 (1980)

23 Eipper, B.A. and Mains, R.E.: Further analysis of post-translational processing of $\beta$-endorphin in rat intermediate pituitary. J. Biol. Chem. 256, 5689-5696 (1981)

24 Piinnenburg, A.J.J. and Van Rossum, J.M.: Stimulation of locomotor activity following injection of dopamine into the nucleus accumbens. J. Pharm. Pharmacol. 25, 1003-1005 (1973)

25 Jackson, D.M., Anden, N.E. and Dahistrom, A.: A function effect of dopamine in the nucleus accumbens and in some other dopaminergic-rich parts of the rat brain. Psychopharmacologia (Berlin) 45, 139-149 (1975)

26 Kelly, P.H., Seviour, P.W. and Iversen, S.D.: Amphetamine and apomorphine responses in rat following 6-OHDA lesions of the nucleus accumbens septi and corpus striatum. Brain Res. 94, 507-522 (1975)

27 Pollard, H., Llorens, C., Bonnet, J.J., Costentin, J. and Schwarts, J.C.: Opiate receptors on mesolimbic dopaminergic neurons. Neurosci. Lett. 7, 295-299 (1977) 